\title{
Rol de enfermería durante la vacunación contra la COVID-19
}

\section{Nursing role during COVID-19 vaccination}

Janet Mercedes Arévalo-Ipanaqué 1,a

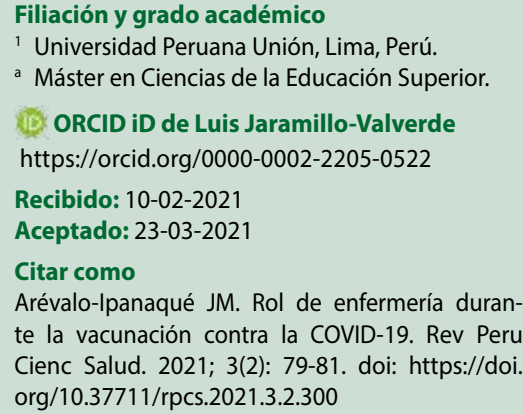

Desde la aparición de la COVID-19 en diciembre del 2019 y su declaración como pandemia en los meses siguientes, esta enfermedad lleva más de un año causando zozobra en la población mundial debido a su alta transmisibilidad acompañada de la ausencia de un tratamiento eficaz. La capacidad del virus es tal que su reproducción básica, un indicador de transmisibilidad del virus, ha sido estimada con un valor promedio de 3,28 y una mediana de 2,79 por lo que se asume que, en un entorno sin medidas de contención, una persona infectada podría contagiar a más de dos personas en un lapso de tres a cuatro días ${ }^{(1)}$.

El impacto de esta pandemia provocó que la comunidad científica mundial centre sus esfuerzos en buscar su control; así, en menos de cinco meses descifraron el genoma del virus, rastrearon su origen y aún siguen proponiendo una serie de medidas para su tratamiento, lo que incluye una carrera sin precedentes en la elaboración de 118 propuestas de vacuna ${ }^{(2)}$. De este modo, en diciembre del 2020 , Rusia se convirtió en el primer país en inmunizar masivamente a su población con su vacuna Sputnik $V$ y el segundo país en iniciar la vacunación masiva fue Reino Unido, con la vacuna de Pfizer/Biontech ${ }^{(3)}$.

En Latinoamérica, Argentina inició el 29 de diciembre del 2020 su campaña de inoculación voluntaria para el personal sanitario luego de aprobar el uso de emergencia de la vacuna Sputnik V. En Chile, el 24 de diciembre se inició la inoculación del personal sanitario y de adultos mayores con la vacuna de Pfizer/Biontech. Brasil y Ecuador iniciaron su vacunación hacia finales de enero del 2021 con la vacuna China Coronavac y Pfizer/Biontech respectivamente (4). En Perú, el 9 de febrero del 2021 se inició la vacunación con Sinopharm a los profesionales de salud.

En este contexto es necesario destacar que, desde siempre, la vacunación es una de las actividades que caracteriza la labor de enfermería. Los profesionales de enfermería han participado en innumerables campañas de vacunación, han orientado a la población y han difundido información sobre inmunizaciones; estando a cargo de dichos consultorios, estrategias y programas en todo el mundo. El rol que cumple el profesional enfermero es fundamental en todos los aspectos que competen a la inmunización debido a que posee los conocimientos, habilidades y actitudes que le permiten desarrollar de forma integral su función de inmunización, desde la gestión o planificación hasta la aplicación, conservación, gestión de los residuos $y$ acciones de control ${ }^{(5)}$. 
Los mismos organismos internacionales de salud reconocen que todos los profesionales involucrados en la implementación de la vacuna COVID-19 deben contar con los conocimientos y habilidades adecuados para garantizar la administración segura y eficiente de la vacuna contra la COVID-19(6).

Es así que a partir del inicio de la campaña de vacunación contra la COVID-19 en el mundo, son los enfermeros los que han demostrado su capacidad de organización y liderazgo. Si bien es cierto, se ha requerido ayuda de los demás grupos profesionales e incluso de las fuerzas armadas, la enfermería no deja de cumplir su rol característico de cuidado en la cadena de frio, manipulación, administración, educación y vigilancia de eventos y reacciones; todas estas son funciones que siguen cumpliendo con la habilidad y competencia ganados por la experiencia.

Sin embargo, el inicio de la vacunación masiva a la población civil trae para los enfermeros retos aún mayores como enfrentarse a la duda de la población, a las campañas informativas que ponen en tela de juicio la eficacia de las vacunas, a discriminar los efectos adversos atribuidos a la vacunación de los que acompañan a la ansiedad y estrés de la población, a educar sobre los cuidados posvacunación y las segundas dosis.

Es en la experiencia previa de vacunación donde los profesionales de enfermería se han enfrentado a un sinnúmero de situaciones complejas y especiales en las que han tenido que decidir sobre la idoneidad o no de la vacunación; y ello les ha sido posible debido a que poseen suficiente cantidad de información que les permite decidir sobre la conveniencia, contraindicación o excepcionalidad de las vacunas. En pocas palabras, las enfermeras poseen el conocimiento y la experiencia que les proporciona rapidez de razonamiento en el proceso de toma de decisión vacunal, tomando un carácter automático o intuitivo ${ }^{(7)}$.

Al mismo tiempo, es oportuno señalar que desde que existe la vacunación han existido también sus detractores, no solo de la inmunización en general, sino también de alguna vacuna en concreto; por lo general, amparadas en argumentos que consideran la presencia de adyuvantes, combinación de varias vacunas, reacciones adversas, posible asociación con determinadas enfermedades, entre otros relacionados a mitos, creencias filosóficas o religiosas, rumores e información sin sustento científico. Esto demuestra la necesidad de brindar adecuada educación a la población, con estandarización de los mensajes que proporcionan los equipos de vacunación y adecuada elección de los medios y recursos informativos empleados, siendo necesario asegurar la capacitación óptima de los profesionales que atienden a los usuarios ${ }^{(8)}$. Ante ello, la enfermería posee amplias habilidades para la consejería y resolución de problemas comunes de vacunación ${ }^{(9)}$. Hoy más que nunca hace falta reorientar las actividades educativas con adecuadas estrategias que impliquen la selección de la información brindada y la forma de trasmisión de la misma por los canales de comunicación apropiados.

En conclusión, ante el reto de lograr la ansiada inmunidad masiva luchando contra los estigmas y la presión de la población en una campaña de vacunación masiva sin precedentes, la experticia de la enfermería lograda a cargo de los programas de inmunizaciones, es una fortaleza que debe apreciarse y una oportunidad para lograr los resultados deseados en la campaña actual de vacunación contra la COVID-19.

\section{REFERENCIAS}

1. Ying Liu AA, Gayle A, Wilder-Smith JR The reproductive number of COVID-19 is higher compared to SARS coronavirus [El número reproductivo de COVID-19 es mayor en comparación con el coronavirus del SARS]. Journal of Travel Medicine [Internet] 2020; 27, (2): 1-4 [Consultado 2021 Mar 1] Disponible en: https://doi.org/10.1093/jtm/ taaa021

2. Durán JC, Martínez C, Mejía D. El papel de la nanociencia y la nanotecnología en el marco de la pandemia de COVID-19. Nano [Internet] 2021; 14(27): e0023 [Consultado 2021 Mar 11] Disponible en: https://doi.org/10.22201/ ceiich.24485691e.2021.27.69647

3. Sánchez VT. COVID-19: estos son los países que ya iniciaron la vacunación masiva. France 24. 2020 Dic 12 [Internet] [Consultado 2021 Marzo 5] Disponible en: https:// www.france24.com/es/programas/ciencia-y-tecnolog\%C3\%ADa/20201210-COVID-19-estos-son-los-pa\%C3\%ADses-que-ya-iniciaron-la-vacunaci\%C3\%B3n-masiva

4. Redacción Gestión. COVID-19: ¿Cuál es la situación actual de la vacuna en el Perú y demás países de Sudamérica? Gestión. 2021 Ene 23 [Internet] [Consultado 2021 Marzo 2] Disponible en: https https://gestion.pe/mundo/COVID-19-cual-es-la-situacion-actual-de-la-vacunacontra-el-coronavirus-en-el-peru-y-demas-paises-desudamerica-nndc-noticia/

5. Ruiz Antúnez, E. Enfermería y vacunación, la importancia de la prescripción. Rev. enferm. CyL [Internet] 2011; 3(1) [Consultado 2021 Mar 1] Disponible en: http://revistaenfermeriacyl.com/index.php/revistaenfermeriacyl/ article/download/64/45+\&cd=6\&hl=es\&ct=clnk\&gl=pe

6. Organización Panamericana de la Salud, OPS. Vacunas contra la COVID-19 [Internet] [Consultado 2021 Marzo 4] Disponible en: https://www.paho.org/es/vacunas-contra-COVID-19 
7. Fernández M, Jiménez L, Santamaría JM, Gómez JL, González A, Monsalvo E. Conceptualización de la toma de decisiones en el cuidado: acercamiento desde la vacunación. Ene. [Internet] 2015 Dic; 9(3) [Consultado 2021 Mar 9] Disponible en: http://dx.doi.org/10.4321/S1988348X2015000300012

8. Morice A, Ávila-Agüero ML. Mitos, creencias y realidades sobre las vacunas. Acta pediátr. costarric [Internet] 2008 Ene; 20(2): 60-64 [Consultado2021 Mar 11] Disponible en: http://www.scielo.sa.cr/scielo.php?script=sci_arttext\&pid=S1409-00902008000200001\&lng=en

9. Soriano J, Labordena C, Gutiérrez MD, Fabregat E, Colomer J, Bargall F. ¿Quién realiza los controles de salud en la Comunidad Valenciana?: propuestas de mejora. Rev Pediatr Aten Primaria [Internet] 2016 Mar; $^{\text {; }}$ 18(69): 17-24 [Consultado 2021 Mar 11] Disponible en: http://scielo.isciii.es/scielo.php?script=sci_arttext\&pi$\mathrm{d}=$ S1139-76322016000100004\&Ing=es 